\title{
Anaesthetic considerations in the child with Menkes' syndrome
}

The author presents and discusses the anaesthetic implications of a four-month-old infant with Menkes' syndrome who required tracheostomy. Menkes' syndrome is an X-linked recessive disorder of copper absorption and metabolism. Defective processing of copper results in abnormalities of several enzyme systems leading to severe dysfunction of multiple organ systems. Due to the progressive nature of this disorder and its severe effects on several different organ systems, most importantly the central nervous system, these children frequently require anaesthetic care during imaging procedures such as MRI or during various surgical operations. The high prevalence of seizure disorders, gastroesophageal reflux with the risk of aspiration, and airway complications related to poor pharyngeal muscle control are of concern to the anaesthetist. In addition, defective collagen formation, similar to that seen in EhlerDanlos syndrome, may be present. Identification of these associated conditions during the preoperative examination will guide the selection of appropriate, safe anaesthetic care for these children.

L'auteur présente et discute les implications anesthésiques d'une trachéostomie effectuée chez un enfant de quatre mois porteur d'un syndrome de Menkes. Ce syndrome génétique transmis par un mode récessif sur le chromosome $X$, produit un désordre d'absorption et de métabolisme du cuivre. Il en résulte des anomalies de nombreux systèmes enzymatiques et

Key words

BRAIN: convulsions;

COMPLICATIONS: convulsions;

SYNDROMES: Menkes'.

From the Division of Pediatric Anesthesiology/Critical Care Medicine, Vanderbilt University, Nashville, Tennessee.

Address correspondence to: Dr. Joseph D. Tobias,

Vanderbilt University, Department of Pediatrics, Division of Pediatric Critical Care, Medical Center North T-0118, Nashville, Tennessee 37232.

Accepted for publication 4th May, 1992.
Joseph D. Tobias MD

une dysfonction pluriorganique sévère. La nature progressive de cette maladie et son effet multisystémique débilitant oblige ces enfants à subir fréquemment des interventions radiologiques (résonance magnétique) et chirurgicale sous anesthésie. Parmi les considérations anesthésiques, on retrouve la haute prévalence de troubles épileptiques, le reflux gastrooesophagien avec risque d'aspiration et l'obstruction des voies aériennes secondaire à un mauvais contrôle des muscles pharyngés. De plus, une formation anormale du collagène, semblable à celle du syndrome d'Ehler-Danlos, peut être présente. L'identification des conditions associées à ce syndrome au cours de l'évaluation préopératoire facilite le choix d'une technique anesthésique appropriée et sans danger pour les enfants atteints de cette maladie.

Menkes' kinky hair disease is an an X-linked neurodegenerative disorder, originally described in 1962 by Menkes and associates. ${ }^{1}$ Clinical characteristics include growth and developmental retardation, seizures, abnormal hair and progressive cerebral degeneration. The onset is generally within the first two months of life with death in most cases by the age of three years due to intractable seizures or pneumonia. Although the exact cellular defect has yet to be identified, Danks and co-workers were the first to find decreased serum copper and caeruloplasmin concentrations suggesting that the disorder was the result of a defect in the intestinal absorption of copper. ${ }^{2}$ The diagnosis is suggested by the typical clinical features and is confirmed by the presence of low serum levels of copper and caeruloplasmin.

Due to the progressive nature of this disorder and its severe effects on several different organ systems, most importantly the central nervous system, these children frequently require anaesthetic care during imaging procedures or during various surgical operations. A four month old who required tracheostomy is presented and the anaesthetic implications of this disorder are discussed.

\section{Case report}

The patient was the term product of an uncomplicated 
pregnancy, labour, and delivery. The neonatal course was complicated by pneumonia and respiratory failure due to sepsis with Group B Streptococcus. This required tracheal intubation and mechanical ventilation for five days. Following extubation, inspiratory stridor was noted and an evaluation of the upper airway was planned. However, the stridor resolved over the ensuing $48 \mathrm{hr}$ and no further investigation was initiated. Further problems during the neonatal period included the onset of generalized, tonicclonic seizures which were controlled with phenobarbital. The remainder of the neurological examination was unremarkable except for persistent hypotonia. Both the seizures and the hypotonia were initially attributed to the episode of neonatal sepsis. The infant was eventually discharged home taking phenobarbital to control the seizures with follow-up visits planned. Following discharge, the infant was noted to feed poorly and his physical growth was delayed.

At three months of age, upper respiratory symptoms developed including mild inspiratory stridor that necessitated hospital admission for observation. Over the ensuing $48 \mathrm{hr}$, upper airway obstruction increased and respiratory failure developed. Tracheal intubation and mechanical ventilation were required. Initial laryngoscopy revealed a normal upper airway, but a $3.5 \mathrm{~mm}$ endotracheal tube (ETT) could not be passed due to subglottic narrowing. The trachea was intubated with a $3.0 \mathrm{~mm}$ ETT. No air leak was noted around the tube at a pressure of $30 \mathrm{~cm} \mathrm{H}_{2} \mathrm{O}$. Following this, attempts at extubation (over a four-week period) were unsuccessful despite various therapeutic manoeuvres including the administration of aerosolized racemic epinephrine, intravenous dexamethasone, and $30 \%$ oxygen in $70 \%$ helium. Rigid bronchoscopy revealed a 20 to $30 \%$ narrowing of the subglottic area with no other abnormalities. Further evaluation of the infant revealed sparse, abnormally formed scalp hair which suggested the diagnosis of Menkes' syndrome. This was later confirmed by low serum copper and ceruloplasmin concentrations. After these failed attempts at extubation, the infant was scheduled for tracheostomy on the following day.

Preoperative medications included the child's usual morning dose of phenobarbital $(8 \mathrm{mg} \mathrm{po})$ in addition to metoclopramide $\left(0.1 \mathrm{mg} \cdot \mathrm{kg}^{-1}\right)$ and ranitidine $(1.5$ $\left.\mathrm{mg} \cdot \mathrm{kg}^{-1}\right)$. Anaesthetic induction consisted of thiopentone $\left(4 \mathrm{mg} \cdot \mathrm{kg}^{-1}\right)$ and fentanyl $\left(2 \mu \mathrm{g} \cdot \mathrm{kg}^{-1}\right)$. Muscle relaxation was achieved with pancuronium $\left(0.1 \mathrm{mg} \cdot \mathrm{kg}^{-1}\right)$. Anaesthesia was maintained with isoflurane (expired concentration 0.4 to $1.0 \%$ ) in oxygen. Following the operation, which lasted $45 \mathrm{~min}$, the infant was transported back to the paediatric ICU. Mechanical ventilation was weaned over the ensuing $18 \mathrm{hr}$ and oxygen saturation remained at 94 to $96 \%$ on room air. The tracheostomy was changed on postoperative day \#5 and the infant was transferred to the inpatient ward.

\section{Discussion}

A four-month-old infant with Menkes' syndrome who required general anaesthesia during upper respiratory endoscopy and tracheostomy placement is presented. Many of the clinical signs and symptoms of this disorder are related to the defective function of enzymes that require copper as a cofactor. This includes depigmentation of hair and skin due to defective tyrosinase function, defective collagen formation due to defective lysyl oxidase function, kinky hair with defective monoamine oxidase function, hypothermia due to dysfunction of cytochrome oxidase, and skeletal demineralization and rickets related to defective ascorbate oxidase function.

Despite the fact that $30 \mathrm{yr}$ has elapsed since the first reported case, the aetiological basis of Menkes' syndrome remains unknown. The characteristic cellular defect is the abnormal distribution of tissue copper. Although intestinal absorption of copper is abnormal, parenteral administration does not result in return of normal enzymatic function or disappearance of the clinical features. The defect appears to be abnormal copper transport across cellular membranes. Defective intracellular copper leads to dysfunction in several copper-dependent enzyme systems. Pathological changes related to defective collagen formation include aneurysm formation and vessel tortuosity in the systemic circulation and intracranially. Histological examination reveals degeneration of both grey and white matter with focal gliosis. It is unknown whether the central nervous system changes relate to these vascular changes or the underlying copper defect.

The major anaesthetic implications of this disorder are related to its effects on the central nervous system. The majority of these patients have seizures, which frequently require more than one anticonvulsant. Preoperative measurement of serum anticonvulsant concentrations is recommended with adjustments as needed to ensure therapeutic levels. Perioperative management should also include the continuation of these medications including the usual morning doses and intraoperative administration as needed. Although intravenous administration is possible for phenobarbital or phenytoin, alternative routes are needed when patients are unable to tolerate oral administration of other anticonvulsants following surgery. Rectal administration is one option for several anticonvulsants including carbamazepine, valproic acid, clonazepam, and diazepam. ${ }^{3,4}$

Progressive CNS deterioration may be accompanied by gastroesophageal reflux (GER) and recurrent aspiration. Although this patient had no symptoms suggestive of 
GER, it was felt that the likelihood of GER was high enough to warrant the preoperative administration of ranitidine and metoclopramide. It is suggested that these agents be used even in patients that are already intubated to prevent acid aspiration.

There are no previous discussions concerning the occurrence of airway problems in children with Menkes' syndrome. It is likely that this patient developed viral laryngotracheobronchitis with subglottic oedema. Although the degree of subglottic narrowing was mild with an airway diameter 70 to $80 \%$ expected, this narrowing combined with generalized hypotonia most likely led to upper airway obstruction that resulted in respiratory failure. It is suggested that patients without an artificial airway might be at risk for postoperative upper airway obstruction related to hypotonia of the pharyngeal musculature in the presence of the residual effects of anesthetic agents. Due to these risks, extended postoperative monitoring $(24 \mathrm{hr})$ with pulse oximetry is recommended. This may be best accomplished in an intermediate care unit since frequent suctioning and positioning may also be required to avoid postoperative respiratory complications.

Aside from its neurological implications, the other major impact of Menkes' syndrome on perioperative care is its similarity to Ehler-Danlos syndrome. ${ }^{5}$ Due to defective lysyl oxidase, a copper-containing enzyme involved in the cross-linking of collagen, these patients may have capillary fragility and associated conditions as described in Ehler-Danlos syndrome. ${ }^{6,7}$ The anaesthetic implication of this includes the increased risk of haemorrhage during surgery. Although increased bleeding is a documented concern in patients with Ehler-Danlos syndrome, this risk is theoretical in patients with Menkes' syndrome since there are no large series of patients undergoing surgery. However, the same cellular defect is present in both syndromes. Although cardiovascular manifestations such as mitral valve regurgitation, vascular aneurysms, and cardiac conduction disturbances are well described in Ehler-Danlos syndrome, they have not been described in Menkes' syndrome.

Although there appears to be no best choice when considering anaesthetic induction agents, the use of propofol is not recomended until the possible association of propofol with perioperative seizures and other abnormal neurological sequelae is resolved. ${ }^{8}$

Several choices exist for maintenance anaesthesia without a particular advantage of any specific technique. Intraoperative monitoring should be determined by the anticipated surgical procedure. We chose to use routine intraoperative monitoring including precordial stethoscope, pulse oximetry, electrocardiogram, non-invasive blood pressure cuff, and end-tidal carbon dioxide measurement. Invasive monitoring may be indicated for more involved surgical procedures. In addition, careful monitoring of body temperature is recommended as well as measures to avoid hypothermia such as warming of infused fluids, regulation of the operating room temperature, and humidification of inhaled gases. This is particularly relevant in children with Menkes' syndrome since they are prone to develop hypothermia. In addition, the general cachectic state of many of these patients leaves them with little or no body fat and therefore at further risk for hypothermia.

The choice of muscle relaxant (depolarizing versus nondepolarizing) is more controversial. We were unable to find any contraindications to the use of succinylcholine. However, due to the risks of hyperkalaemia following succinylcholine in patients with upper motor neuron diseases, ${ }^{9}$ the use of nondepolarizing agents is suggested. Large doses of vecuronium may be required in patients receiving chronic therapy with either phenobarbital or phenytoin. ${ }^{10}$ Therefore, it was more convenient to use pancuronium as its duration of action should be less affected by medications that induce hepatic enzymes.

The provision of postoperative analgesia should also be part of the anaesthetic technique. Although regional anaesthetic techniques offer several advantages, compared with parenteral narcotics, the possibility of capillary fragility due to defective collagen formation appears to be a relative contraindication to these techniques in patients with Menkes' syndrome as in patients with Ehler-Danlos syndrome. ${ }^{6,7}$ As there is no information concerning this issue, parenteral narcotics appear to be the most appropriate choice. Small doses of intravenous narcotics (e.g., morphine 0.03 to $0.05 \mathrm{mg} \cdot \mathrm{kg}^{-1}$ ) repeated as needed are suggested. Although the effects of narcotics in these patients have not been examined, we speculate that due to altered central control of respiration, these patients may have an increased sensitivity to the respiratory depressant effects of narcotics. Therefore, monitoring of respiratory function (pulse oximetry, respiratory rate) is recommended when administering narcotics in this setting.

In summary, the anaesthetic management of a fourmonth-old infant with Menkes' syndrome is presented. Of concern to the anaesthetist is the high prevalence of seizure disorders, poor pharyngeal coordination, and the presence of GER with the risk of aspiration. Identification of these conditions during the preoperative examination will guide the selection of appropriate, safe anaesthetic care for these children.

\section{References}

1 Menkes JH. Heredodegenerative diseases. In: Menkes JH (Ed.). Textbook of Child Neurology, 2nd ed., Philadelphia: Lea \& Febiger, 1980: 110-47.

2 Danks DM, Campbell PE, Stevens BJ, Mayne V, 
Cartwright E. Menkes' kinky hair syndrome. An inherited defect in copper absorption with widespread effects. Pediatrics 1972; 50: 188-201.

3 Woody RC, Laney SM. Rectal anticonvulsants in pediatric practice. Pediatr Emerg Care 1988; 4: 112-5.

4 Snead OC, Miles $M V$. Treatment of status epilepticus in children with rectal valproate. J Pediatr 1985; 106: 323-5.

5 Kuivaniemi H, Peltonen L, Kivirikko KI. Type IX EhlerDanlos syndrome and Menke's syndrome: the decrease in lysyl oxidase activity is associated with a corresponding deficiency in the enzyme protein. Am J Hum Genet 1985; 37: 798-808.

6 Tobias JD. Anesthetic implications of Ehler-Danlos syndrome: interpleural anesthesia for postoperative analgesia. Anesthesia Review (in press).

7 Dolan P, Sisko F, Riley E. Anesthetic considerations for Ehler-Danlos syndrome. Anesthesiology 1980; 152: 266-9.

8 Collier C, Kelly $K$. Propofol and convulsions: the evidence mounts. Anaesth Intensive Care 1991; 19: 573-5.

9 Cooperman LH, Strobel GE Jr, Kennel EM. Massive hyperkalemia after administration of succinylcholine. Anesthesiology 1978; 32: 161-5.

10 Ornstein E, Matteo RS, Schwartz AE, Silverberg PA, Young WL, Diag $J$. The effects of phenytoin on the magnitude and duration of neuromuscular block following atracurium and vecuronium. Anesthesiology 1987; 67: 191-3. 